\title{
Circulating Nitrite and Nitrate are Associated with Job-Related Fatigue in Women, but not in Men
}

\author{
Jiro Takaki \\ Department of Public Health and Occupational Medicine, Mie University Graduate School of \\ Medicine, 2-174 Edobashi, Tsu, Mie 514-8507, Japan; E-Mail: jirosinryounaika-tky@ umin.ac.jp; \\ Tel.: +81-59-232-1111 (ext. 6372); Fax: +81-59-231-5012
}

Received: 29 May 2013; in revised form: 23 June 2013 / Accepted: 26 June 2013 /

Published: 5 July 2013

\begin{abstract}
A recent study indicated that serum nitrite and nitrate $\left(\mathrm{NO}_{\mathrm{x}}\right)$ is inversely associated with general fatigue. The purpose of this study was to confirm the negative association between nitric oxide (NO) and fatigue and to examine whether NO can prevent fatigue caused by job strain. The subjects, 570 workers (272 men and 298 women), answered self-administered questionnaires and underwent a medical examination. Job strain was measured using the Job Content Questionnaire. Fatigue was evaluated using the Profile of Mood States. Venous blood samples were collected after overnight fasting. Plasma $\mathrm{NO}_{\mathrm{x}}$ concentration was determined by the ozone-based chemiluminescence assay. Plasma $\mathrm{NO}_{\mathrm{x}}$ levels were significantly $(p<0.05)$ negatively associated with fatigue even after adjustment for job strain and potential confounders in women, but not in men. Significant $(p<0.05)$ interactions showed that, in women, as the level of the job strain worsened, fatigue was exacerbated, but the plasma $\mathrm{NO}_{\mathrm{x}}$ seemed to buffer the association, even after adjustment for potential confounders and the interaction between job strain and vegetable intake. In women, NO seemed to be inversely associated with fatigue and to buffer the association between job strain and fatigue, but not in men.
\end{abstract}

Keywords: interaction; demands-control model; fatigue; gender difference; job strain; nitric oxide 


\section{Introduction}

Nitric oxide (NO), the mediator of endothelium-dependent relaxation, is produced by the oxidation of L-arginine in an enzymatic reaction catalyzed by nitric oxide synthase (NOS). The measurement of NO itself is extremely difficult, because of its radical nature and very short half-life in vivo, most likely shorter than $0.1 \mathrm{~s}[1,2]$. NO is instantly converted to nitrite $\left(\mathrm{NO}_{2}{ }^{-}\right)$and nitrate $\left(\mathrm{NO}_{3}{ }^{-}\right)[1,2]$. NOS activity can be determined only in tissue or cell homogenates [1]. Therefore, determination of stable end products of $\mathrm{NO}$ radical, $\mathrm{NO}_{2}{ }^{-}$and $\mathrm{NO}_{3}{ }^{-}\left(\mathrm{NO}_{\mathrm{x}}\right)$, in plasma is most often used as an index of systemic NO formation [1-5]. Plasma $\mathrm{NO}_{\mathrm{x}}$ levels reflect not only NO production and NOS activity, but also an imbalance in oxidant/antioxidant mechanisms with reduced antioxidant defenses and the amount of ingested nitrates [3,5]. Excess visceral adiposity induces excess generation of reactive oxygen species (ROS) and diminished antioxidant defense mechanisms [6]. Cigarette smoke contains abundant ROS [7]. Excessive chronic exposure to alcohol usually results in decreased levels of antioxidant defenses [8]. It is well-established that exercise increases ROS formation in skeletal muscle [9]. To control for the imbalance in oxidant/antioxidant mechanisms and the amount of ingested nitrates, measurement should be made after overnight fast and obesity, cigarette smoking, alcohol consumption, and exercise should be adjusted for in the analysis.

Recently, it has been indicated that serum $\mathrm{NO}_{\mathrm{x}}$ concentrations are inversely associated with scores of general fatigue evaluated by the Multidimensional Fatigue Inventory, a self-rating scale [10], in healthy elderly subjects [3]. NO plays an essential role in vascular homeostasis, metabolic regulation, and immune processes [2,3]. NO can be cytoprotective under physiological and pathophysiological conditions $[11,12]$. In the central nervous system, NO production is associated with cognitive function, its role spanning from the induction and maintenance of synaptic plasticity to the control of sleep, appetite, body temperature and neurosecretion, and physiological amounts of NO are believed to be neuroprotective [13]. Moreover, NO has been hypothesized to have a role in the etiology of chronic fatigue syndrome [14]. Thus, physiological amounts of NO seem to play a role in prevention of fatigue in healthy individuals.

In this study, preventive effect of NO on fatigue in healthy workers was hypothesized. The inverse association between $\mathrm{NO}$ and fatigue was confirmed in working population using plasma $\mathrm{NO}_{\mathrm{x}}$ levels. Moreover, in previous studies, high job strain evaluated using the demands-control model [15] seemed to cause fatigue [16-18]. Thus, whether NO can prevent fatigue caused by job strain was also assessed. Previous studies have suggested that there are gender differences in NO production/release or in responses to NO [19-21]. Thus, the data in men and women were analyzed separately.

\section{Methods}

\subsection{Subjects}

The subjects in this study were recruited from all the full-time workers $(n=1,003)$ at 16 organizations comprising a manufacturing company, an office of a distribution company, supermarkets, and a health care institution in Japan. The purpose and procedure of the survey were explained to the participants in the documents. Written informed consent was obtained from all participants. Approximately 2 weeks after distribution of the self-administered questionnaires, they were collected from 605 workers 
(response rate: $60.3 \%$ ) at their medical examination. Because of missing data, 570 workers (272 men and 298 women; 19 workers in the manufacturing company, 138 workers in the office of a distribution company, 286 workers in the supermarkets, and 127 workers in the health care institution) were included in the analyses. This study was approved by the ethics committee of the Okayama University Graduate School of Medicine, Dentistry, and Pharmaceutical Sciences, and was performed according to the Declaration of Helsinki.

\subsection{Parameters}

\subsubsection{Job Strain}

Job strain was measured using the Job Content Questionnaire (JCQ), developed by Karasek based on the demands-control model [15]. The JCQ includes scales for job demands (five items; range, 12-48) and job control (nine items; range, 24-96), with a four-point response option from 1 (strongly disagree) to 4 (strongly agree). The JCQ was translated into Japanese and the internal consistency reliability and factor- and construct-validity have been reported to be acceptable [22]. A job strain index, which is calculated as job demands divided by job control, has been used as an indicator of job strain; higher scores indicate greater strain [23]. To place inverse imbalance of the same magnitude (for example $0.5 \times$ and $2 \times$ ) in the same distance from $X$ (when job demands and job control are equivalent) the index was logarithmically transformed.

\subsubsection{Fatigue}

Fatigue was evaluated using the Profile of Mood States (POMS), which is a valid and reliable self-administered questionnaire that assesses the mood of a subject [24]. The POMS includes scales for fatigue (seven items; range, 0-28), with a five-point response option. The POMS was translated into Japanese and the validity and reliability have been confirmed to be excellent [25].

\subsubsection{Plasma $\mathrm{NO}_{\mathrm{x}}$}

Venous blood samples were collected after overnight fasting for at least $10 \mathrm{~h}$ during the subjects' medical examination. Plasma samples were stored at $-80{ }^{\circ} \mathrm{C}$ until analysis. Plasma $\mathrm{NO}_{\mathrm{x}}$ concentration was determined by the ozone-based chemiluminescence assay [26]. To ensure accurate analysis, during sample collection, light exposure was minimized and distilled water with no $\mathrm{NO}_{2}{ }^{-}$content was used. The intra- and inter-assay variability over two months expressed using coefficient of variations was reliably $<10 \%$.

\subsubsection{Covariates}

Age, body mass index (BMI), cigarette smoking, alcohol consumption, exercise, and total vegetable intake were included in the analyses as covariates. They could be associated with plasma $\mathrm{NO}_{\mathrm{x}}$ levels [2,27-30]. Age was calculated from the date of answering the questionnaires and the date of birth. BMI was calculated as body weight $(\mathrm{kg})$ divided by the square of body height $\left(\mathrm{m}^{2}\right)$, which were measured at the medical examination. The definition of smokers that was described in a previous study 
showing the association between plasma $\mathrm{NO}_{\mathrm{x}}$ and cigarette smoking was used [29]. The variable of cigarette smoking was "heavy smokers, current smokers with a smoking history of $>20$ pack years $=2$; moderate smokers, current smokers with a smoking history of 1 to 20 pack years $=1$; nonsmokers or ex-smokers, others than moderate or heavy smokers $=0$ ". The variable of alcohol consumption was as follows: Nondrinkers $=0$; those who drink once per week or less, but not nondrinkers $=1$; those who drink more than once per week $=2$. The variable of exercise was "less than once per week $=0$; once per week or more $=1$ ". To control for the effect of $\mathrm{NO}_{\mathrm{x}}$ from dietary sources, total vegetable intake ( $\mathrm{g} /$ day) measured by a validated food frequency questionnaire [31] was included in the analyses. In the general population, approximately $70 \%$ of the daily dietary exposure to nitrate comes from vegetables [30]. Though venous blood samples were collected after overnight fasting for at least $10 \mathrm{~h}, \mathrm{NO}_{\mathrm{x}}$ from dietary sources might not be fully excreted [5]. The adjustment can also control for the effects of vitamins, minerals, and polyphenols in vegetables on fatigue.

\subsection{Statistical Analysis}

Differences in continuous variables were compared between men and women using unpaired $t$-tests. Ordinal categorical variables were compared using chi-square test. Then, Pearson's correlation coefficients were calculated for the correlations between continuous variables, and Spearman's correlation coefficients were calculated for the correlations that included ordinal categorical variables. Multivariate associations of fatigue with plasma $\mathrm{NO}_{\mathrm{x}}$ and job strain were assessed with regression analyses.

Hierarchical regression analyses were employed to examine the hypothesis that NO functioned as an effect modifier in the relationships between job strain and fatigue. In model 1 , the variables of job strain, and plasma $\mathrm{NO}_{\mathrm{x}}$ levels and the product of the variables of job strain and plasma $\mathrm{NO}_{\mathrm{x}}$ levels were entered as independent variables in a multiple regression model with fatigue as the dependent variable. In model 2, all the aforementioned covariates and the product of the variables of job strain and total vegetable intake were added to the independent variables to control for the possible preventive effect of vegetable intake (i.e., the effect of $\mathrm{NO}_{\mathrm{x}}$, vitamins, minerals, and polyphenols in vegetables) on fatigue. In accordance with Jaccard et al. [32], the continuous variables used as the independent variables were mean-centered. To further examine this interaction, graphic displays of the regression models were also created based on the recommendations described by Cohen et al. [33]. The regression lines and predicted values illustrating the significant interactions were constructed from the intercepts, the unstandardized regression coefficients, the mean values, and the standard deviations (SDs). Scores were plotted at the mean, low (1 SD below the mean), and high (1 SD above the mean) values. The scores have been calculated to an accuracy of six figures of decimal points.

All the $p$ values were two-tailed, and $p<0.05$ was the threshold for significance. All statistical analyses were performed with SPSS version 20.0.

\section{Results}

Participant characteristics according to gender are shown in Table 1. Age, BMI, cigarette smoking, alcohol consumption, exercise, total vegetable intake, job control, job strain, plasma $\mathrm{NO}_{\mathrm{x}}$, and fatigue were significantly different depending on gender. 
Table 1. Participant characteristics according to gender.

\begin{tabular}{|c|c|c|c|c|c|c|c|}
\hline & \multicolumn{3}{|c|}{$\operatorname{Men}(\mathbf{n}=272)$} & \multicolumn{3}{|c|}{ Women $(n=298)$} & \multirow[t]{2}{*}{$p^{a}$} \\
\hline & Mean & SD & Range & Mean & SD & Range & \\
\hline Age (years) & 43.6 & 10.1 & $20.0-67.7$ & 40.4 & 10.6 & $18.6-65.4$ & $<0.001$ \\
\hline $\operatorname{BMI}\left(\mathrm{kg} / \mathrm{m}^{2}\right)$ & 23.7 & 3.5 & $16.1-37.2$ & 21.6 & 3.6 & $14.5-39.7$ & $<0.001$ \\
\hline Total vegetable intake (g/day) & 125.1 & 80.3 & $0-645$ & 144.2 & 93.0 & 4-557 & 0.009 \\
\hline Plasma $\mathrm{NO}_{\mathrm{x}}(\mu \mathrm{mol} / \mathrm{L})$ & 29.4 & 16.1 & $7.4-97.3$ & 25.0 & 13.5 & $8.5-92.3$ & $<0.001$ \\
\hline \multicolumn{8}{|l|}{ Job Content Questionnaire } \\
\hline Job demands & 32.0 & 5.5 & $12-48$ & 32.4 & 5.6 & $12-48$ & 0.45 \\
\hline Job control & 65.7 & 10.4 & 24-90 & 62.2 & 10.7 & 24-90 & $<0.001$ \\
\hline Job strain index ${ }^{b}$ & -0.312 & 0.087 & $-0.624--0.020$ & -0.283 & 0.106 & $-0.684-0.151$ & $<0.001$ \\
\hline \multirow[t]{2}{*}{ Fatigue $^{c}$} & 7.8 & 7.2 & 0-28 & 11.2 & 7.6 & 0-28 & \multirow[t]{2}{*}{$<0.001$} \\
\hline & $\mathrm{n}$ & $\%$ & & $\mathrm{n}$ & $\%$ & & \\
\hline \multicolumn{7}{|l|}{ Cigarette smoking } & \multirow[t]{3}{*}{$<0.001$} \\
\hline Moderate smoker ${ }^{d}$ & 83 & 30.5 & & 41 & 13.8 & & \\
\hline Heavy smoker ${ }^{\mathrm{e}}$ & 81 & 29.8 & & 6 & 2.0 & & \\
\hline Alcohol consumption & & & & & & & $<0.001$ \\
\hline Once per week or less, but not none & 64 & 23.5 & & 128 & 43.0 & & \\
\hline More than once per week & 140 & 51.5 & & 50 & 16.8 & & \\
\hline Exercising once per week or more & 107 & 39.3 & & 61 & 20.5 & & $<0.001$ \\
\hline
\end{tabular}

${ }^{a}$ Continuous variables were compared using the unpaired $t$-test, and categorical variables were compared using chi-square test; ${ }^{b}$ Calculated as job demands divided by job control and logarithmically transformed; ${ }^{\mathrm{C}}$ Evaluated using the Profile of Mood States; ${ }^{\mathrm{d}}$ Current smokers with a smoking history of 1 to 20 pack years; ${ }^{\mathrm{e}}$ Current smokers with a smoking history of $>20$ pack years. 
Table 2. Correlations ${ }^{\text {a }}$ of the variables used in the study in men.

\begin{tabular}{|c|c|c|c|c|c|c|c|c|c|c|c|}
\hline & 1 & 2 & 3 & 4 & 5 & 6 & 7 & 8 & 9 & 10 & 11 \\
\hline 1. Age & 1 & & & & & & & & & & \\
\hline 2. BMI & 0.06 & 1 & & & & & & & & & \\
\hline 3. Cigarette smoking & $0.23 * *$ & -0.04 & 1 & & & & & & & & \\
\hline 4. Alcohol consumption & 0.10 & -0.09 & $0.13 *$ & 1 & & & & & & & \\
\hline 5. Exercise & 0.08 & -0.06 & $-0.13 *$ & 0.00 & 1 & & & & & & \\
\hline 6. Total vegetable intake & $0.15 *$ & 0.07 & 0.05 & 0.07 & -0.00 & 1 & & & & & \\
\hline 7. Plasma $\mathrm{NO}_{\mathrm{x}}$ & 0.03 & $0.18^{*}$ & $-0.15 *$ & -0.04 & $0.17 *$ & 0.06 & 1 & & & & \\
\hline 8. Job demands & $-0.25 * *$ & -0.11 & $-0.13 *$ & -0.10 & -0.02 & 0.06 & -0.03 & 1 & & & \\
\hline 9. Job control & 0.07 & -0.07 & 0.03 & $0.20 * *$ & 0.09 & -0.00 & 0.07 & $0.32 * *$ & 1 & & \\
\hline 10. Job strain index & $-0.28 * *$ & -0.03 & -0.12 & $-0.22 * *$ & -0.08 & 0.06 & -0.09 & $0.58 * *$ & $-0.57 * *$ & 1 & \\
\hline 11. Fatigue & $-0.20 * *$ & -0.03 & -0.09 & -0.10 & -0.11 & -0.02 & -0.04 & $0.45 * *$ & -0.01 & $0.39 * *$ & 1 \\
\hline
\end{tabular}

a Spearman's correlation coefficients were calculated for the correlations that included variables of cigarette smoking, alcohol consumption, and exercise. For the other correlations, Pearson's correlation coefficients were calculated; * $p<0.05 ; * *<<0.001$.

Table 3. Correlations ${ }^{\text {a }}$ of the variables used in the study in women.

\begin{tabular}{|c|c|c|c|c|c|c|c|c|c|c|c|}
\hline & 1 & 2 & 3 & 4 & 5 & 6 & 7 & 8 & 9 & 10 & 11 \\
\hline 1. Age & 1 & & & & & & & & & & \\
\hline 2. BMI & $0.20 * *$ & 1 & & & & & & & & & \\
\hline 3. Cigarette smoking & -0.05 & -0.10 & 1 & & & & & & & & \\
\hline 4. Alcohol consumption & 0.00 & -0.03 & 0.11 & 1 & & & & & & & \\
\hline 5. Exercise & 0.11 & 0.05 & -0.06 & 0.05 & 1 & & & & & & \\
\hline 6. Total vegetable intake & $0.14 *$ & 0.04 & -0.08 & -0.08 & $0.15 *$ & 1 & & & & & \\
\hline 7. Plasma $\mathrm{NO}_{\mathrm{x}}$ & $0.17 *$ & -0.01 & $-0.18 *$ & -0.03 & $0.25 * *$ & $0.21 * *$ & 1 & & & & \\
\hline 8. Job demands & -0.01 & 0.07 & 0.03 & 0.08 & -0.07 & 0.02 & -0.04 & 1 & & & \\
\hline 9. Job control & 0.11 & $0.13 *$ & -0.04 & 0.02 & 0.11 & 0.06 & -0.04 & $0.14 *$ & 1 & & \\
\hline 10. Job strain index & -0.11 & -0.04 & 0.07 & 0.05 & $-0.13 *$ & -0.02 & 0.02 & $0.64 * *$ & $-0.66 * *$ & 1 & \\
\hline 11. Fatigue & -0.05 & -0.03 & 0.03 & 0.01 & $-0.20 * *$ & $-0.20 * *$ & $-0.16 *$ & $0.42 * *$ & -0.07 & $0.34 * *$ & 1 \\
\hline
\end{tabular}

a Spearman's correlation coefficients were calculated for the correlations that included variables of cigarette smoking, alcohol consumption, and exercise. For the other correlations, Pearson's correlation coefficients were calculated; * $p<0.05 ; * * p<0.001$. 
Correlations of the variables used in the study in men are shown in Table 2. Plasma $\mathrm{NO}_{\mathrm{x}}$ levels positively correlated with BMI and exercise, and negatively correlated with cigarette smoking with statistical significance. Plasma $\mathrm{NO}_{\mathrm{x}}$ levels did not significantly correlate with fatigue in men. Correlations of the variables in women are shown in Table 3. Plasma $\mathrm{NO}_{\mathrm{x}}$ levels positively correlated with age, exercise and total vegetable intake, and negatively correlated with cigarette smoking and fatigue with statistical significance. Job strain and fatigue showed a significant positive correlation in both genders.

Results of multiple regression analyses are shown in Table 4. Plasma $\mathrm{NO}_{\mathrm{x}}$ levels were significantly associated with fatigue after adjustment for job strain and covariates in women, but not in men. Job strain was significantly associated with fatigue in women (standardized regression coefficient, $\beta=0.33,95 \%$ confidence interval (CI) 0.23 to 0.44$)$ and in men $(\beta=0.35,95 \%$ CI 0.24 to 0.47$)$. Both $\beta$ s were very similar.

Table 4. Multiple regression analyses with fatigue ${ }^{\mathrm{a}}$ as a dependent variable.

\begin{tabular}{|c|c|c|c|c|}
\hline & \multicolumn{2}{|c|}{ Men } & \multicolumn{2}{|c|}{ Women } \\
\hline & $\beta^{b}$ & $\mathbf{p}$ & $\beta^{\mathbf{b}}$ & p \\
\hline Age (years) & -0.06 & 0.36 & 0.03 & 0.59 \\
\hline BMI $\left(\mathrm{kg} / \mathrm{m}^{2}\right)$ & -0.03 & 0.64 & -0.03 & 0.62 \\
\hline \multicolumn{5}{|l|}{ Cigarette smoking } \\
\hline \multicolumn{5}{|l|}{ Nonsmoker or ex-smoker ${ }^{c}$ (reference) } \\
\hline Moderate smoker ${ }^{\mathrm{d}}$ & 0.06 & 0.37 & -0.05 & 0.36 \\
\hline Heavy smoker ${ }^{\mathrm{e}}$ & -0.07 & 0.27 & 0.03 & 0.57 \\
\hline \multicolumn{5}{|l|}{ Alcohol consumption } \\
\hline \multicolumn{5}{|l|}{ None (reference) } \\
\hline Once per week or less, but not none & -0.10 & 0.16 & -0.08 & 0.21 \\
\hline More than once per week & -0.08 & 0.24 & 0.01 & 0.85 \\
\hline \multicolumn{5}{|l|}{ Exercise } \\
\hline \multicolumn{5}{|l|}{ Less than once per week (reference) } \\
\hline Once per week or more & -0.06 & 0.27 & -0.10 & 0.08 \\
\hline Total vegetable intake (g/day) & -0.05 & 0.44 & -0.16 & 0.006 \\
\hline Job strain index ${ }^{\mathrm{f}}$ & 0.35 & $<0.001$ & 0.33 & $<0.001$ \\
\hline Plasma $\mathrm{NO}_{\mathrm{x}}(\mu \mathrm{mol} / \mathrm{L})$ & 0.02 & 0.77 & -0.14 & 0.02 \\
\hline Adjusted $\mathrm{R}^{2}$ & \multicolumn{2}{|c|}{$0.149(p<0.001)$} & \multicolumn{2}{|c|}{$0.161(p<0.001)$} \\
\hline
\end{tabular}

Results of multiple regression analyses including interactions are shown in Table 5. The interaction between plasma $\mathrm{NO}_{\mathrm{x}}$ and fatigue significantly contributed to both regression Models 1 and 2 in women, but not in men. The regression lines and predicted values illustrating the significant interactions in both Models 1 and 2 show that, in women, as the level of the job strain worsened, fatigue was exacerbated, but the plasma $\mathrm{NO}_{\mathrm{x}}$ seemed to buffer the association (Figure 1). 
Table 5. Multiple regression analyses with fatigue ${ }^{\mathrm{a}}$ as a dependent variable including interactions.

\begin{tabular}{|c|c|c|c|c|c|c|c|c|}
\hline & \multicolumn{4}{|c|}{ Men } & \multicolumn{4}{|c|}{ Women } \\
\hline & \multicolumn{2}{|c|}{ Model 1} & \multicolumn{2}{|c|}{ Model 2} & \multicolumn{2}{|c|}{ Model 1} & \multicolumn{2}{|c|}{ Model 2} \\
\hline & $\boldsymbol{\beta}^{\mathbf{b}}$ & $\mathbf{p}$ & $\beta^{\mathbf{b}}$ & $\mathbf{p}$ & $\boldsymbol{\beta}^{\mathbf{b}}$ & $\mathbf{p}$ & $\boldsymbol{\beta}^{\mathbf{b}}$ & $\mathbf{p}$ \\
\hline Plasma $\mathrm{NO}_{\mathrm{x}}(\mu \mathrm{mol} / \mathrm{L})$ & -0.03 & 0.58 & 0.00 & 0.99 & -0.16 & 0.004 & -0.12 & 0.03 \\
\hline Job strain index ${ }^{c}$ & 0.41 & $<0.001$ & 0.37 & $<0.001$ & 0.36 & $<0.001$ & 0.35 & $<0.001$ \\
\hline Job strain index ${ }^{\mathrm{c}} \times$ plasma $\mathrm{NO}_{\mathrm{x}}$ (interaction) & -0.07 & 0.29 & -0.05 & 0.48 & -0.12 & 0.02 & -0.14 & 0.01 \\
\hline Age (years) & & & -0.06 & 0.36 & & & 0.04 & 0.53 \\
\hline BMI $\left(\mathrm{kg} / \mathrm{m}^{2}\right)$ & & & -0.03 & 0.66 & & & -0.03 & 0.53 \\
\hline \multicolumn{9}{|l|}{ Cigarette smoking } \\
\hline \multicolumn{9}{|l|}{ Nonsmoker or ex-smoker ${ }^{\mathrm{d}}$ (reference) } \\
\hline Moderate smoker ${ }^{\mathrm{e}}$ & & & 0.06 & 0.36 & & & -0.05 & 0.34 \\
\hline Heavy smoker ${ }^{\mathrm{f}}$ & & & -0.07 & 0.30 & & & 0.03 & 0.62 \\
\hline \multicolumn{9}{|l|}{ Alcohol consumption } \\
\hline \multicolumn{9}{|l|}{ None (reference) } \\
\hline Once per week or less, but not none & & & -0.09 & 0.22 & & & -0.07 & 0.22 \\
\hline More than once per week & & & -0.08 & 0.28 & & & 0.01 & 0.91 \\
\hline \multicolumn{9}{|l|}{ Exercise } \\
\hline \multicolumn{9}{|l|}{ Less than once per week (reference) } \\
\hline Once per week or more & & & -0.06 & 0.27 & & & -0.11 & 0.06 \\
\hline Total vegetable intake (g/day) & & & -0.05 & 0.38 & & & -0.17 & 0.004 \\
\hline Job strain index ${ }^{c} \times$ total vegetable intake (interaction) & & & -0.06 & 0.33 & & & 0.02 & 0.73 \\
\hline Adjusted $\mathrm{R}^{2}$ & \multicolumn{2}{|c|}{$0.143(p<0.001)$} & \multicolumn{2}{|c|}{$0.148(p<0.001)$} & \multicolumn{2}{|c|}{$0.149(p<0.001)$} & \multicolumn{2}{|c|}{$0.175(p<0.001)$} \\
\hline
\end{tabular}

${ }^{a}$ Evaluated using the Profile of Mood States; ${ }^{\mathrm{b}}$ Standardized regression coefficient; ${ }^{\mathrm{c}}$ Calculated as job demands divided by job control evaluated using the Job Content Questionnaire and logarithmically transformed; ${ }^{\mathrm{d}}$ Others than moderate or heavy smokers. ${ }^{\mathrm{e}}$ Current smokers with a smoking history of 1 to 20 pack years; ${ }^{\mathrm{f}}$ Current smokers with a smoking history of $>20$ pack years. 
Figure 1. Regression lines and predicted values illustrating the significant interactive effects of job strain and the plasma $\mathrm{NO}_{\mathrm{x}}$ level on fatigue according to the regression Models 1 and 2 in women.
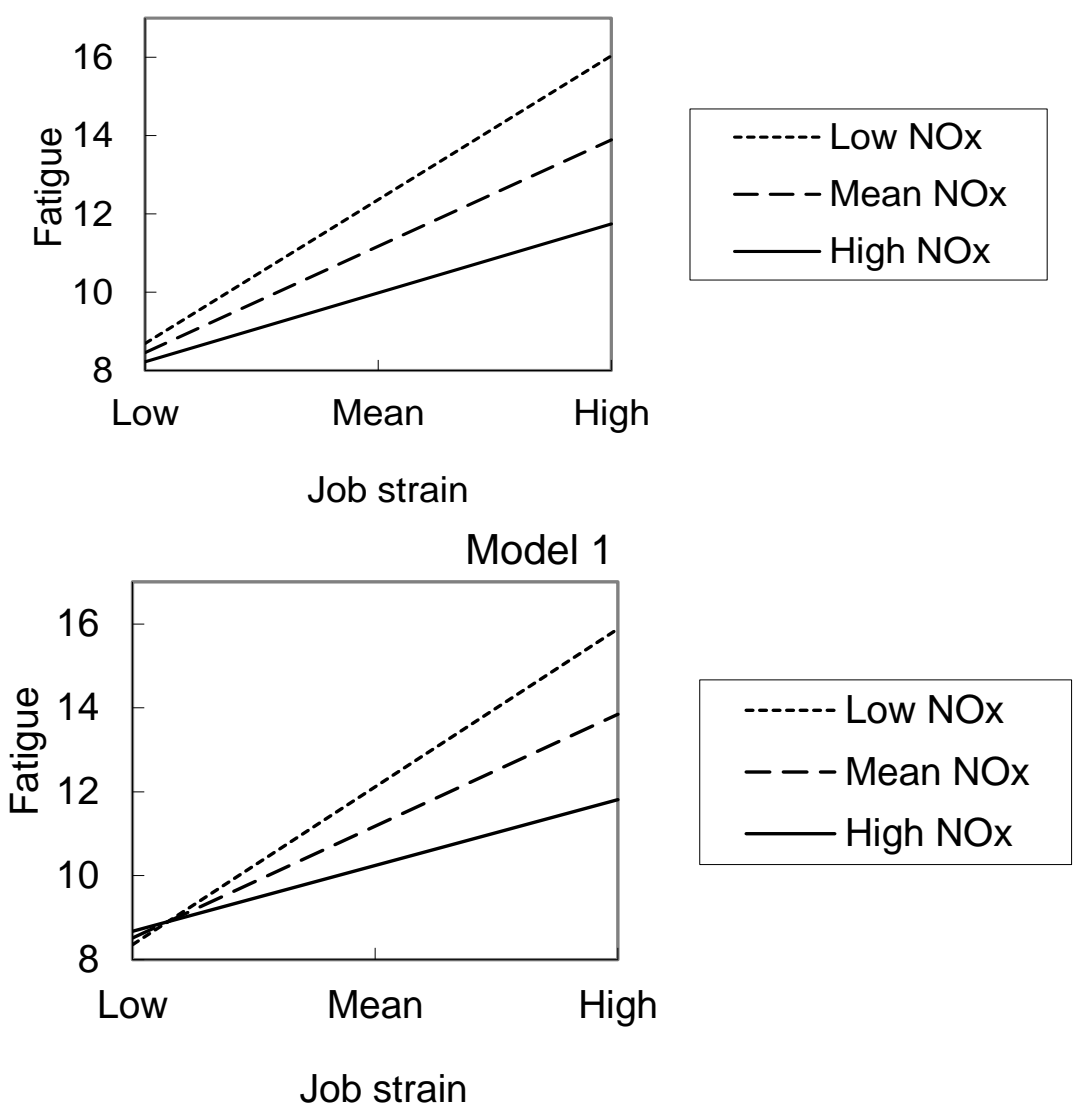

Model 2

\section{Discussion}

$\mathrm{NO}$ (evaluated by plasma $\mathrm{NO}_{\mathrm{x}}$ ) seemed to be negatively associated with fatigue in women, but not in men. In agreement with this result, in a previous study in which about $70 \%$ of the subjects were women, the serum $\mathrm{NO}_{\mathrm{x}}$ concentration was negatively associated with general fatigue $(\beta=-0.115)$ after adjustment for age, gender, BMI, and life-time history of major depression [3].

Furthermore, NO seemed to buffer the association between job strain and fatigue in women, even after adjustment for potential confounders and the interaction between job strain and vegetable intake. In this study, the relationship between job strain and fatigue in men and women was similar. Thus, the cause for the gender difference seems to involve NO. Previous studies have suggested that there are gender differences in NO production/release or in responses to NO. For example, the rise in plasma $\mathrm{NO}_{\mathrm{x}}$ concentration in males after $\mathrm{KNO}_{3}$ ingestion appeared significantly lower compared with females [19]. Estradiol supplementation improves endothelium-dependent vasodilation in women, probably because of augmented NO production/release, but not in men [20]. Whole-body production of NO was greater in healthy premenopausal women than in men under ambulatory conditions [21]. Future studies on gender differences in NO production/release or in responses to NO may explain the mechanism of the findings in this study. 
This study has some limitations. First, because this study used a cross-sectional design, it was difficult to determine the causal nature of the observed relationships. Longitudinal research is necessary to clarify the causality. Second, because this study used convenience sampling, the results may not be applicable to the entire workforce. However, because subjects were recruited from four entirely different industries and the response rate was more than $50 \%$, some generalizability can be expected. For example, the relationship between job strain and fatigue seen in this study was consistent with previous studies [16-18]. This finding of a positive association between age and $\mathrm{NO}_{\mathrm{x}}$ levels in women, but not in men, is also consistent with a previous study [2]. The negative association between cigarette smoking and plasma $\mathrm{NO}_{\mathrm{x}}$ shown in this study has also been previously reported [28]. Third, in this study, percentages of smokers, drinkers, and those who exercise were much larger in men than in women. The adjustments for cigarette smoking, alcohol consumption, and exercise using two or three categories might not be sufficient and lead to the failure to detect associations in men.

\section{Conclusions}

In women, NO seemed to be inversely associated with fatigue and to buffer the association between job strain and fatigue, but not in men.

\section{Acknowledgments}

This study was supported in part by a Research Grant (No. 23500802) from the Ministry of Education, Science, and Culture of Japan. The author gratefully appreciates technical contributions from H. Irimajiri, A. Hayama, R. Sauriasari, S. Kanbara, and N. Sakano.

\section{Conflict of Interest}

The author declares no conflict of interest.

\section{References}

1. Moshage, H.; Kok, B.; Huizenga, J.R.; Jansen, P.L. Nitrite and nitrate determinations in plasma: A critical evaluation. Clin. Chem. 1995, 41, 892-896.

2. Ghasemi, A.; Zahedi Asl, S.; Mehrabi, Y.; Saadat, N.; Azizi, F. Serum nitric oxide metabolite levels in a general healthy population: Relation to sex and age. Life Sci. 2008, 83, 326-331.

3. Capuron, L.; Schroecksnadel, S.; Féart, C.; Aubert, A.; Higueret, D.; Barberger-Gateau, P.; Layé, S.; Fuchs, D. Chronic low-grade inflammation in elderly persons is associated with altered tryptophan and tyrosine metabolism: Role in neuropsychiatric symptoms. Biol. Psychiatry 2011, 70, 175-182.

4. Sauriasari, R.; Sakano, N.; Wang, D.H.; Takaki, J.; Takemoto, K.; Wang, B.; Sugiyama, H.; Sato, Y.; Takigawa, T.; Takahashi, N.; et al. C-reactive protein is associated with cigarette smoking-induced hyperfiltration and proteinuria in an apparently healthy population. Hypertens. Res. 2010, 33, 1129-1136. 
5. Himeno, M.; Ishibashi, T.; Nakano, S.; Furuya, K.; Kigoshi, T.; Uchida, K.; Nishio, M. A practical procedure for achieving a steady state of $\mathrm{NO}_{\mathrm{x}}$ concentration in plasma: With special reference to the $\mathrm{NO}_{\mathrm{x}}$ content of Japanese daily food. Tohoku J. Exp. Med. 2003, 199, 95-110.

6. Whaley-Connell, A.; Sowers, J.R. Oxidative stress in the cardiorenal metabolic syndrome. Curr. Hypertens. Rep. 2012, 14, 360-365.

7. Pryor, W.A. Cigarette smoke radicals and the role of free radicals in chemical carcinogenicity. Environ. Health Perspect. 1997, 105, 875-882.

8. Zhu, H.; Jia, Z.; Misra, H.; Li, Y.R. Oxidative stress and redox signaling mechanisms of alcoholic liver disease: Updated experimental and clinical evidence. J. Dig. Dis. 2012, 13, 133-142.

9. Powers, S.K.; Jackson, M.J. Exercise-induced oxidative stress: Cellular mechanisms and impact on muscle force production. Physiol. Rev. 2008, 88, 1243-1276.

10. Smets, E.M.; Garssen, B.; Bonke, B.; de Haes, J.C. The Multidimensional Fatigue Inventory (MFI) psychometric qualities of an instrument to assess fatigue. J. Psychosom. Res. 1995, 39, 315-325.

11. Cosby, K.; Partovi, K.S.; Crawford, J.H.; Patel, R.P.; Reiter, C.D.; Martyr, S.; Yang, B.K.; Waclawiw, M.A.; Zalos, G.; Xu, X.; et al. Nitrite reduction to nitric oxide by deoxyhemoglobin vasodilates the human circulation. Nat. Med. 2003, 9, 1498-1505.

12. Lauer, T.; Heiss, C.; Balzer, J.; Kehmeier, E.; Mangold, S.; Leyendecker, T.; Rottler, J.; Meyer, C.; Merx, M.W.; Kelm, M.; et al. Age-dependent endothelial dysfunction is associated with failure to increase plasma nitrite in response to exercise. Basic Res. Cardiol. 2008, 103, 291-297.

13. Calabrese, V.; Mancuso, C.; Calvani, M.; Rizzarelli, E.; Butterfield, D.A.; Stella, A.M. Nitric oxide in the central nervous system: Neuroprotection versus neurotoxicity. Nat. Rev. Neurosci. 2007, 8, 766-775.

14. Pall, M.L. Common etiology of posttraumatic stress disorder, fibromyalgia, chronic fatigue syndrome and multiple chemical sensitivity via elevated nitric oxide/peroxynitrite. Med. Hypotheses 2001, 57, 139-145.

15. Karasek, R.A. Job demands, job decision latitude, and mental strain: Implications for job redesign. Adm. Sci. Q. 1979, 24, 285-308.

16. Wahlstedt, K.; Lindgren, T.; Norbäck, D.; Wieslander, G.; Runeson, R. Psychosocial work environment and medical symptoms among Swedish commercial airline cabin crew. Am. J. Ind. Med. 2010, 53, 716-723.

17. Lindeberg, S.I.; Rosvall, M.; Choi, B.; Canivet, C.; Isacsson, S.O.; Karasek, R.; Ostergren, P.O. Psychosocial working conditions and exhaustion in a working population sample of Swedish middle-aged men and women. Eur. J. Public Health 2011, 21, 190-196.

18. De Lange, A.H.; Kompier, M.A.; Taris, T.W.; Geurts, S.A.; Beckers, D.G.; Houtman, I.L.; Bongers, P.M. A hard day's night: A longitudinal study on the relationships among job demands and job control, sleep quality and fatigue. J. Sleep Res. 2009, 18, 374-383.

19. Kapil, V.; Milsom, A.B.; Okorie, M.; Maleki-Toyserkani, S.; Akram, F.; Rehman, F.; Arghandawi, S.; Pearl, V.; Benjamin, N.; Loukogeorgakis, S.; et al. Inorganic nitrate supplementation lowers blood pressure in humans: Role for nitrite-derived NO. Hypertension 2010, 56, 274-281. 
20. Kawano, H.; Motoyama, T.; Kugiyama, K.; Hirashima, O.; Ohgushi, M.; Fujii, H.; Ogawa, H.; Yasue, H. Gender difference in improvement of endothelium-dependent vasodilation after estrogen supplementation. J. Am. Coll. Cardiol. 1997, 30, 914-919.

21. Forte, P.; Kneale, B.J.; Milne, E.; Chowienczyk, P.J.; Johnston, A.; Benjamin, N.; Ritter, J.M. Evidence for a difference in nitric oxide biosynthesis between healthy women and men. Hypertension 1998, 32, 730-734.

22. Kawakami, N.; Kobayashi, F.; Araki, S.; Haratani, T.; Furui, H. Assessment of job stress dimensions based on the job demands-control model of employees of telecommunication and electric power companies in Japan: Reliability and validity of the Japanese version of job content questionnaire. Int. J. Behav. Med. 1995, 2, 358-375.

23. Landsbergis, P.A.; Schnall, P.L.; Warren, K.; Pickering, T.G.; Schwartz, J.E. Association between ambulatory blood pressure and alternative formulations of job strain. Scand. J. Work Environ. Health 1994, 20, 349-363.

24. McNair, D.M.; Losr, M.; Droppleman, L.E. Profile of Mood States Manual; Educational and Industrial Testing Service: San Diego, CA, USA, 1971.

25. Yokoyama, K.; Araki, S.; Kawakami, N.; Takeshima, T. Production of the Japanese edition of the Profile of Mood States (POMS): Assessment of reliability and validity. Jpn. J. Public Health 1990, 37, 913-918.

26. MacArthur, P.H.; Shiva, S.; Gladwin, M.T. Measurement of circulationg nitrite and S-nitrosothiols by reductive chemiluminescence. J. Cromatogr. B 2007, 851, 93-105.

27. Sierksma, A.; van der Gaag, M.S.; Grobbee, D.E.; Hendriks, H.F. Acute and chronic effects of dinner with alcoholic beverages on nitric oxide metabolites in healthy men. Clin. Exp. Pharmacol. Physiol. 2003, 30, 504-506.

28. Tsuchiya, M.; Asada, A.; Kasahara, E.; Sato, E.F.; Shindo, M.; Inoue, M. Smoking a single cigarette rapidly reduces combined concentrations of nitrate and nitrite and concentrations of antioxidants in plasma. Circulation 2002, 105, 1155-1157.

29. Node, K.; Kitakaze, M.; Yoshikawa, H.; Kosaka, H.; Hori, M. Reversible reduction in plasma concentration of nitric oxide induced by cigarette smoking in young adults. Am. J. Cardiol. 1997, 79, 1538-1541.

30. Ysart, G.; Miller, P.; Barrett, G.; Farrington, D.; Lawrance, P.; Harrison, N. Dietary exposures to nitrate in the UK. Food Addit. Contam. 1999, 16, 521-532.

31. Takahashi, K.; Yoshimura, Y.; Kaimoto, T.; Kunii, D.; Komatsu, T.; Yamamoto, S. Validation of a food frequency questionnaire based on food groups for estimating individual nutrient intake. Jpn. J. Nutr. 2001, 59, 221-232.

32. Jaccard, J.; Turrisi, R.; Wan, C.K. Interaction Effects in Multiple Regression; Sage: Newbury Park, CA, USA, 1990.

33. Cohen, J.; Cohen, P.; West, S.G.; Aiken, L.S. Applied Multiple Regression/Correlation Analysis for the Behavioral Sciences, 2nd ed.; Erlbaum: Hillsdale, MI, USA, 2003.

(C) 2013 by the authors; licensee MDPI, Basel, Switzerland. This article is an open access article distributed under the terms and conditions of the Creative Commons Attribution license (http://creativecommons.org/licenses/by/3.0/). 